\title{
INEL Support to the Plutonium in Soil Integrated Demonstration (Nevada) Interim Report
}

\author{
Jerry R. Weidner
}

Published September 1992

Idaho National Engineering Laboratory

EG\&G Idaho, Inc.

Idaho Falls, Idaho 83415

\author{
Prepared for the \\ U.S. Department of Energy \\ Office of Environmental Restoration and Waste Management \\ Under DOE Idaho Fleld Office \\ Contract DE-AC07-76ID01570
}


INEL Support to the Plutonium in Soil Integrated Demonstration (Nevada) Interim Report

EGG-WTD-10386

Prepared by:

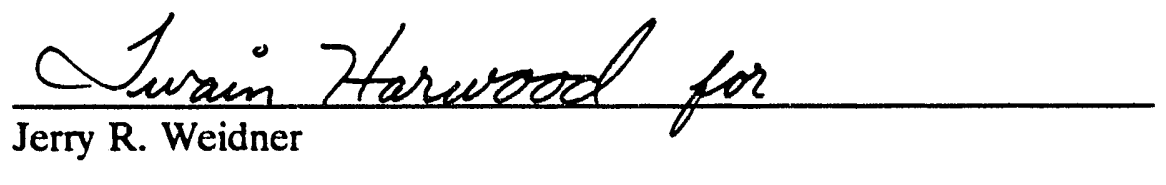

$\frac{9 / 23 / 92}{\text { Date }}$

Approved by:

$\frac{\text { Couture }}{\text { Christine J. Bonzon }}$ Bonze

$\frac{9 / 23 / 92}{\text { Date }}$ 


\begin{abstract}
A grab sample of 14 metric tons of uncontaminated Idaho National Engineering Laboratory (INEL) soil was excavated, packaged, and shipped to the Nevada Test Site for soil separation testing. The grab sample was from the Lost River Settling Area-B, located north-663541.06, east-262153.12, and elevation-5013.83 ft. The sample material contained soil and unconsolidated sediments from the ground surface to approximately $3.3-\mathrm{m}$ deep. The material was collected in exactly the same way and from exactly the same place as material used to landscape and backfill the Radioactive Waste Management Complex at the INEL. Qualitative observations, using polarizing light microscopy, indicated that the principal components of the material are quartz, plagioclase, and calcite. Iron oxide material was present as a coating on most sediment particles. Clay minerals were not observed but are probably present. The diameter of most of the particles was between 10 and $75 \mu \mathrm{m}$. Field observations indicated that the calcite was a cement and occurred in vertical trending veins in the unconsolidated sediments.
\end{abstract}




\section{CONTENTS}

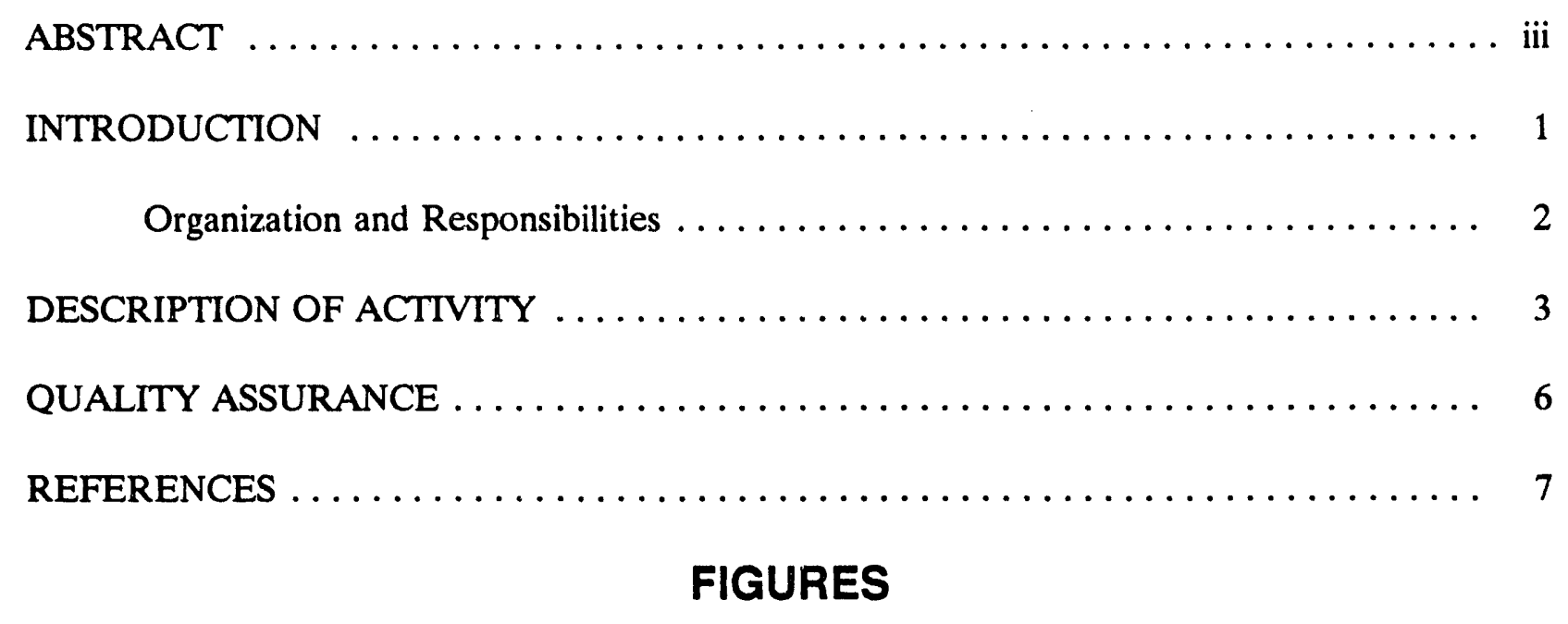

1. Sample site showing the survey stake and the bluff face $\ldots \ldots \ldots \ldots \ldots$

2. Soil excavation and packaging in lined wooden waste boxes $\ldots \ldots \ldots \ldots$ 


\section{INEL Support to the Plutonium in Soil Integrated Demonstration (Nevada) Interim Report}

\section{INTRODUCTION}

The U.S. Department of Energy (DOE) identified a need to develop, test, and demonstrate technologies for the remediation of land surface cleanup of contaminated soil at several DOE sites, including volume reduction of contaminated soil and ultimate disposal of contaminated wastes. Volume reduction is needed to reduce disposal costs and minimize the environmental impact from the construction of new land disposal facilities. The Office of Technology Development (OTD) established integrated demonstrations to fulfill the information and technology needs for planning volume reduction and decontamination of contaminated soils. The objective of Integrated Demonstration A-2, Plutonium in Soils, was to develop and test optimized cleanup systems for surface contamination of large areas, particularly the Nevada Test Site (NTS) and the Tonopa Test Range in Nevada. The effort was expanded to include other DOE sites such as the Idaho National Engineering Laboratory (INEL).

The Plutonium in Soil Integrated Demonstration was designed to test the efficiency of commercially available systems for the physical removal of plutonium and/or heavy metals from contaminated soil. Several vendors tested their soil separating equipment at the NTS using contaminated soil from the NTS, INEL, Rocky Flāts Plant, Oak Ridge National Laboratory, Los Alamos National Laboratory, and Fernald Environmental Management Project. A soil sample of about 14 metric tons was required from each site for testing. The data generated were used to determine the relative soil processing efficiency of the tested soil separation systems.

The planned INEL participation in the Plutonium in Soil Integrated Demonstration was to send at least two soil samples to NTS for testing. One sample was contaminated soil from a site that had yet to be selected. The second soil sample, the subject of this report, was uncontaminated soil excavated from the Lost River Settling Area-B near the Radioactive Waste Management Complex (RWMC).

Uncontaminated soil was sent to the NTS because contaminated soil from the RWMC was not available at the time required, and uncontaminated INEL soil was necessary to set up the processing apparatus at the NTS. Soil from the Lost River Settling Area-B was used to landscape and backfill the RWMC and was probably a major component of the contaminated soil in the RWMC. Therefore, uncontaminated soil from this area was collected and shipped to NTS where it was mixed with plutonium and/or heavy metal surrogates and used to test the soil separation systems. The results allowed the soil separation processes to be ranked according to their relative efficiencies in separating dense materials analogous to plutonium and heavy metals from the soil expected to be found in the INEL's RWMC. 


\section{Organization and Responsibilities}

The Plutonium in Soil Integrated Demonstration program at the INEL is part of the Retrieval and Treatment Technologies Unit in the Waste Technology Development Department of EG\&G Idaho, Inc. Twain E. Harwood was the project manager. The principal investigator, Jerry $R$. Weidner, was responsible for technical activity planning, implementation, and status reporting. Soil excavation and packaging was supervised by Mike Clements, supervisor of the Maintenance and Operations unit at the RWMC. Survey of the sample site was supervised by Robert Sutherlin of MK Ferguson of Idaho Company. 


\section{DESCRIPTION OF ACTIVITY}

The activity reported in this document is the excavation of 14 metric tons of uncontaminated INEL soil from the Lust River Settling Area-B. The soil was taken from an area already under excavation to obtain soil for backfill and landscaping at the RWMC. The soil referred to here is largely unconsolidated sediment, presumably wind blown silt and fine sand, and sediment from past flooding in the settling area, a portion of the Big Lost River flood plain.

The grab sample was taken from the west end of the barrow pit in the Lost River Settling Area-B. The project survey coordinates, north-663541.06, east-262153.12, and elevation-5013.83 ft, were recorded using the North American Datum of 1927 system. The stake, located at ground surface and shown by the arrow in Figure 1, indicates the surveyed excavation location. The bluff face height was approximately $3.3 \mathrm{~m}$. The excavation of t'.le sample was carried out using standard excavation equipment as shown in Figure 2. The sample was excavated from the base of the bluff face (see Figure 1) directly below the survey stake and consisted of material that had collapsed down the face. Thus, the sample contained material from the ground surface to about 3.3-m deep at the barrow pit floor. The bluff face was buff in color and cut by irregular, vertically trending, white appearing veins of hard cemented material. Visual examination suggested that this material made up about $5 \%$ or less of the bluff face. Polarizing light microscopy (discussed below) indicated that the mineral calcite and probably cementing material were present.

The excavation site and method were chosen so that the sample could be taken in a place and manner identical to the material used to backfill and landscape the RWMC. No attempt was made to obtain a representative sample of material from Settling Area-B because the material being used for backfill was collected in a nonrandom manner, and a representative sample had no meaning in that context. The sample was a grab sample.

Seven $64-\mathrm{ft}^{3}(4 \times 4 \times 4-\mathrm{ft})$ wooden waste boxes with plastic liners were filled with excavated soil and shipped by truck to

Renolds Electrical Engineering Co.
Mercury, Nevada, 89023
CO DOE Attention: C. Rosenberry
Deliver to AREA 25 BLDG. 3124

An approximately $25-\mathrm{kg}$ aliquot of soil was retained by Jerry $\mathrm{R}$. Weidner for reference and future work and remains in his control.

A grab sample from the $25-\mathrm{kg}$ aliquot of soil was qualitatively analyzed by Jerry $\mathrm{R}$. Weidner using the polarizing light microscope and oil grain mounts of the material. ${ }^{1}$ The quantities indicated were qualitative visual estimates. Size estimates were made using a calibrated ocu $u_{2} \Delta$ micrometer. The data indicated that the grains were rounded and $\approx 90 \%$ of the grains had diameters between 10 and $75 \mu \mathrm{m}$. The minerals identified consisted of quartz $(\approx 85$ vol\%), plagioclase $(\approx 5$ vol\%), calcite $(\approx 5$ vol\%), biotite (trace), and hematite (trace). No clay minerals were recognized, but they were probably present in minor quantities. This was also indicated by the unusually unweathered condition of the plagiclase. A red-brown stain, probably iron oxide, was often present as a coating on the mineral grains. 


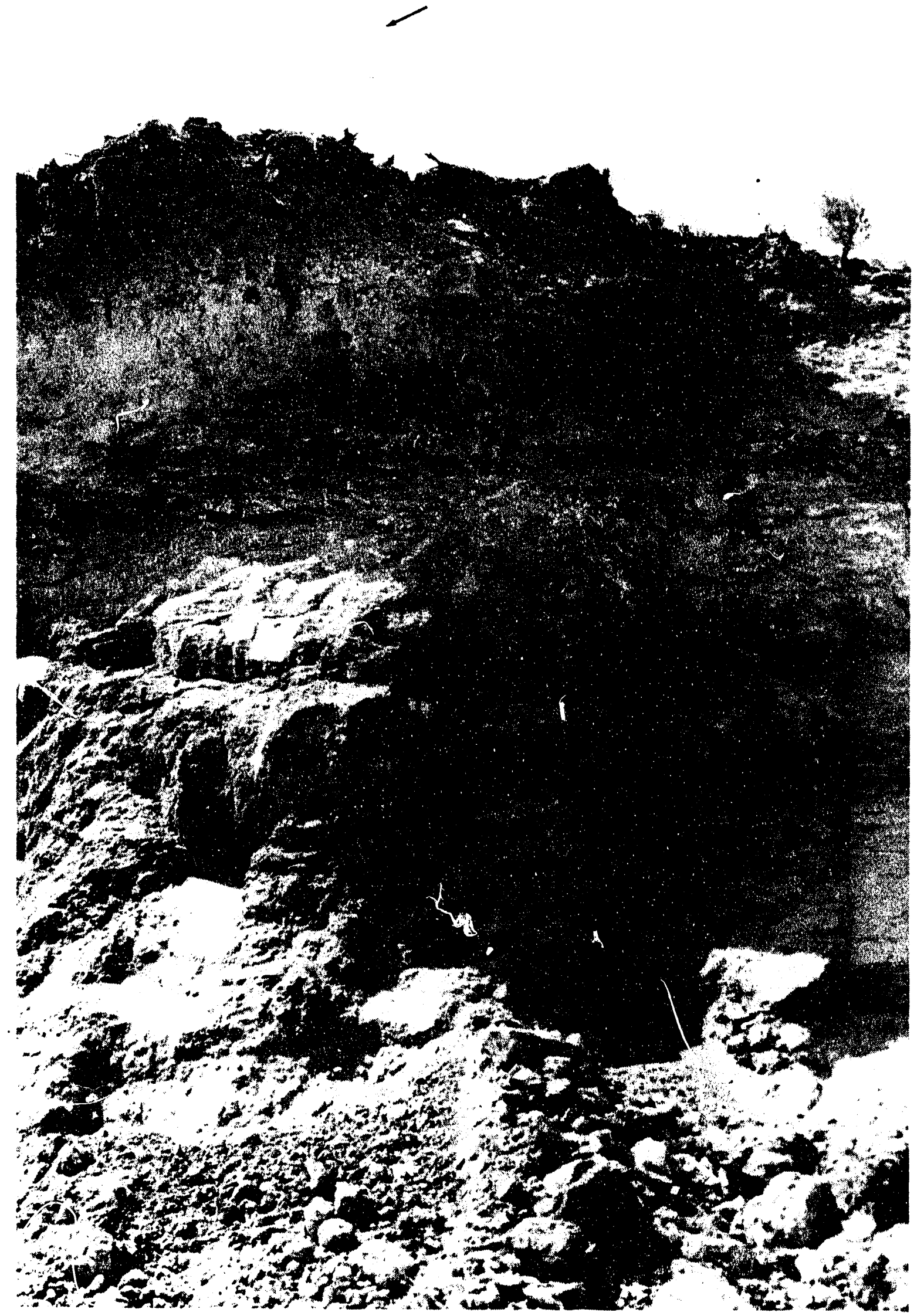

Figure 1. Sample site showing the survey stake and the bluff face. Note the light-colored veining in the bluff face due to cementing material, probably calcite. 


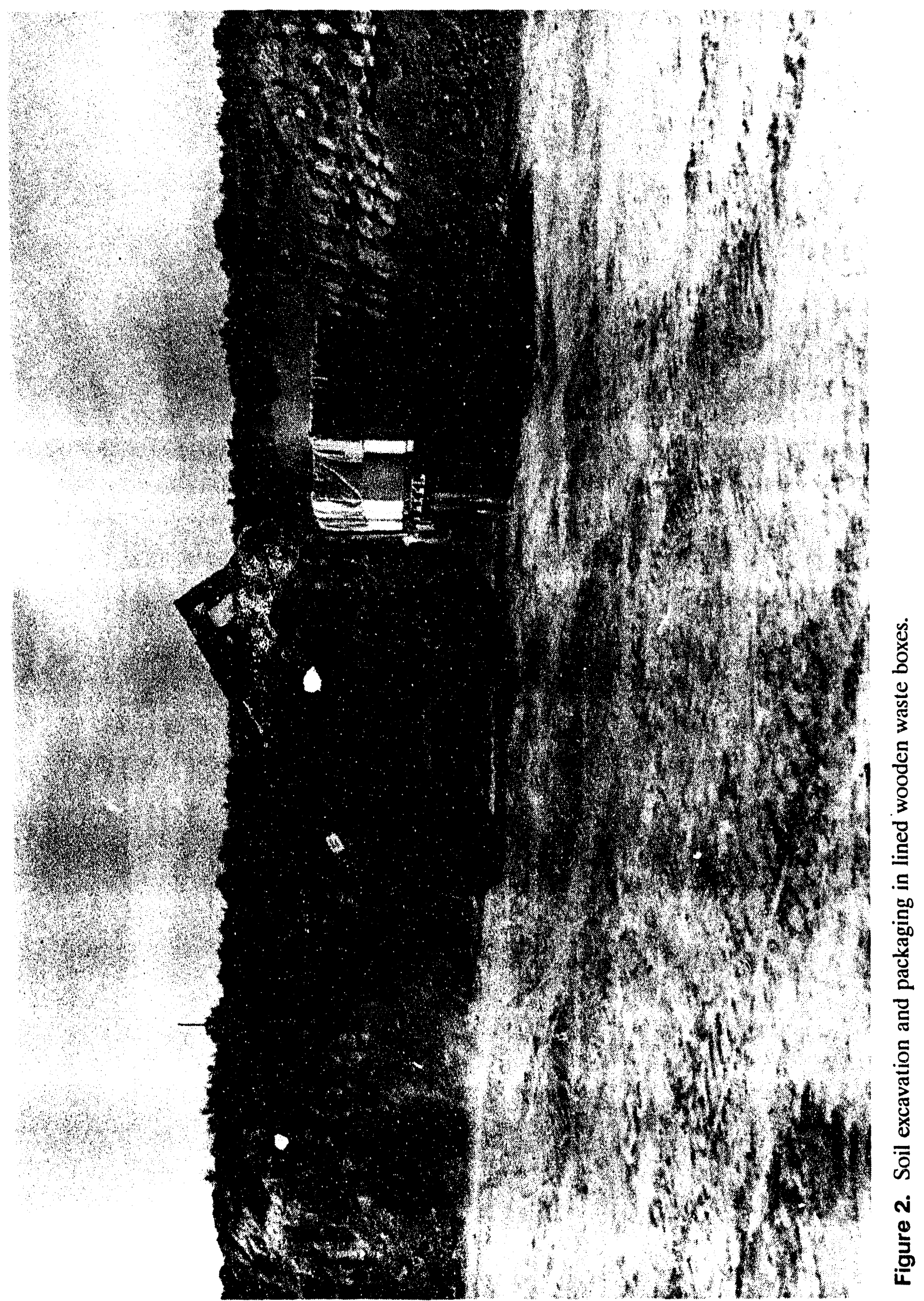




\section{QUALITY ASSURANCE}

The excavation and packaging process was quality assurance (QA) Level I, and the process was observed by the principal investigator. The sample location and area description were recorded by the principal investigator. The microscopy observations were QA Level I and were carried out by the principal investigator. This activity was performed in compliance with the guidance provided in Quality Program Plan-337.

a. Quality Program Plan for the Waste Technology Development Department, Idaho National Engineering Laboratory, EG\&G Idaho, Inc. 


\section{REFERENCES}

1. I. D. Muir, "Microscopy: Transmitted Light," Physical Methods in Derminative Mineralogy, ed. J. Zussman, Academic Press, New York, 1977. 

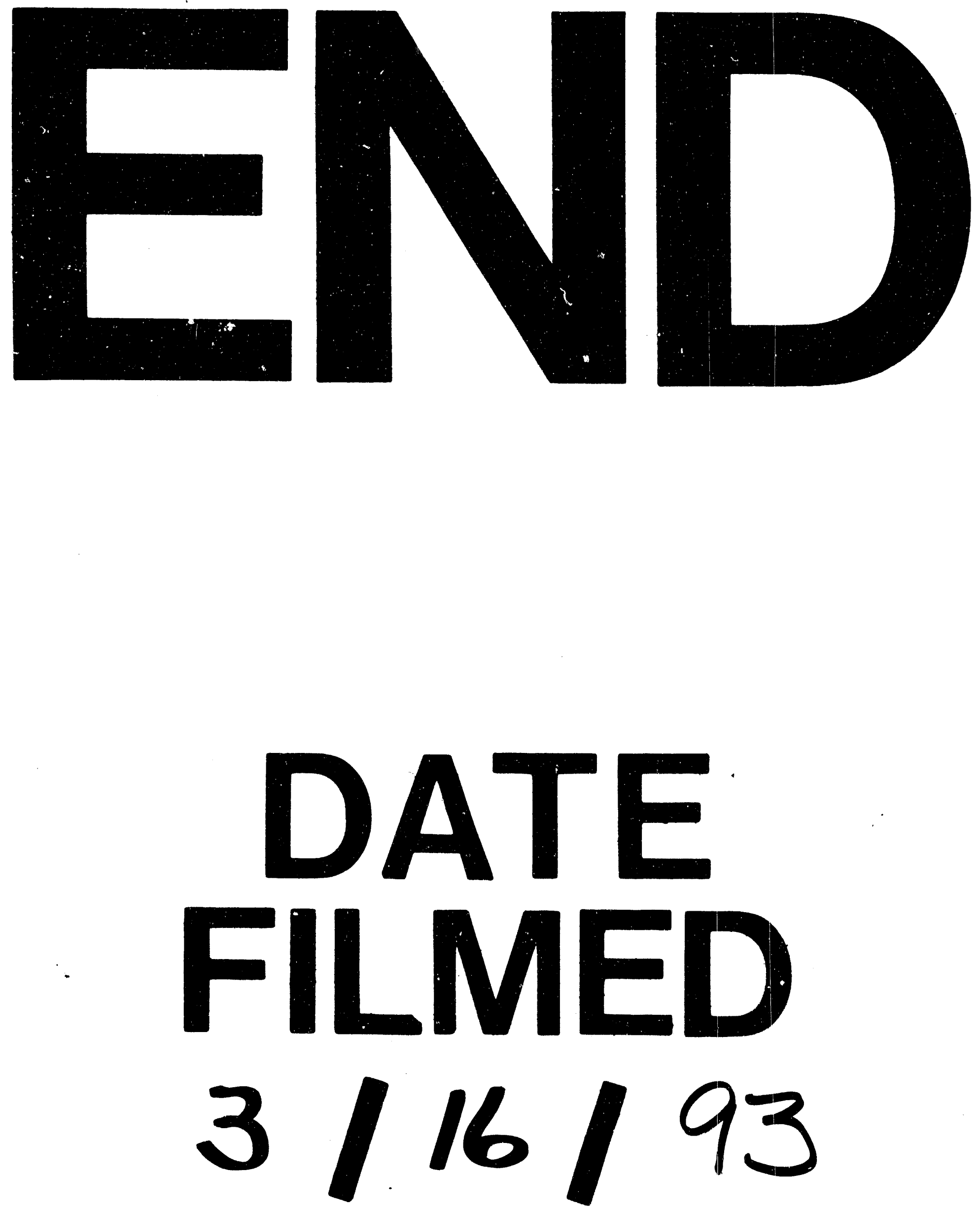

1 
